\title{
Paper
}

\section{Production of High Strength Titanium Alloy through HIP}

\author{
Masashi HAYAKAWA*, Osamu KANOU and Nobuo FUKADA \\ Toho Titanium Co., Ltd., 3-3-5 Chigasaki 253-8510, Japan.
}

Received November 16, 2015; Revised December 10, 2015; Accepted December 10, 2015

\begin{abstract}
A pre-alloyed powder metallurgy method has been investigated in order to produce high-strength titanium alloy at a lower cost than by currently executed blended elemental powder method. Ti-6Al-4V alloy bars containing $3.5 \% \mathrm{Fe}$ and $4 \% \mathrm{Cu}$ of $\phi 22 \mathrm{~mm}$ were produced using Ti-6Al-4V alloy powder as a starting material by hot isostatistic pressing (HIP) followed by forging and hot-rolling. The material densified to almost $100 \%$ density through HIP process. Microstructure after hot rolling at the temperature of $(\alpha+\beta)$ region showed fine equi-axial grains. Tensile characteristics of $\mathrm{Fe}$ and $\mathrm{Cu}$ containing alloys were strongly influenced by heat treatment condition. Just after hot rolling or heat treatment, especially air-cooling, the addition of $\mathrm{Fe}$ and $\mathrm{Cu}$ resulted in high strength but poor elongation. Water-cooled material showed enough elongation but a little bit poorer strength. These tensile characteristics seem to be explained by the $\beta$ phase ratio in the alloy. This result shows that tensile properties of Ti-6Al-4V alloys containing Fe and $\mathrm{Cu}$ can be controlled by heat treatment condition, and possess high potential in the application for airplane and automobile.
\end{abstract}

\section{KEY WORDS}

pre-alloyed powder metallurgy method, titanium alloy, HIP, heat treatment, sintering

\section{Introduction}

Titanium alloy is actually exposed in a severe competition with several structural materials although it is widely used as a corrosion resistant material. Substantial cost reduction is indispensable for a titanium alloy to be used widely in the field of structural material $^{1)}$, and Near Net Shaping using powder metallurgical process becomes to be paid much attention. For example, R. R. Boyer ${ }^{2}$ insisted on the cost reduction in titanium alloy production by a powder metallurgy in a keynote speech at the titanium international conference held in 2011. C. A. Brice ${ }^{3)}$ reported at the same conference that the substantial cost reduction by additive manufacturing was approaching a practical use. It is recently also reported that titanium alloy produced by a powder metallurgical process comes to a practical use by business airplane ${ }^{4)}$. These reports show that titanium alloy produced by a powder metallurgical process is coming to a practical use gradually. The authors are investigating a powder metallurgical process in order to produce high-strength titanium alloy at low cost.

A manufacturing process of titanium alloy by a powder metallurgy is categorized into following two groups, blended elemental powder method and pre-alloyed powder metallurgy method. Currently only blended elemental powder method is reported in a practical use. Blended elemental powder method is the way to use mixed powder

* Corresponding author, E-mail: mhayakawa@toho-titanium.co.jp of alloying elements or a master alloy powder as a raw material. On the other hand, pre-alloyed powder metallurgy method is the way to use pre-alloyed powder as a raw material, in this case, pure titanium powder, alloying element powder or mother alloy powder are not required. Pre-alloyed powder can be obtained by hydrogenation and de-hydrogenation process (HDH process) using relatively cheap titanium alloy turning chips as starting materials. This is the reason why pre-alloyed powder metallurgy method possesses the possibility of low cost production. The comparison between blended elemental powder method and pre-alloyed powder metallurgy method is shown in Table 1.

Many titanium alloys consist of $\beta$ stabilizing elements such as vanadium, molybdenum, chromium, iron, copper etc., and $\alpha$ stabilizing elements represented by aluminum. However, content of iron and copper is restricted at about $1 \%$ and at $2 \%$ in the highest case because these two elements tend to segregate during consolidation. This restriction is caused by ingot melting process and there is no limitation when powder metallurgical process is applied instead of the ingot process. Authors believe that new titanium alloy whose constitution is impossible by an ingot melting process can be produced by powder metallurgical process. The properties of new constitution titanium alloy should possibly be superior to the conventional one.

Authors have reported that addition of high amount of copper to Ti-6Al-4V alloy can be produced without segregation of copper 
Table 1 Comparison between Blended Elemental Powder Method and Pre-alloyed Powder Metallurgy Method.

\begin{tabular}{cll}
\hline Methods & \multicolumn{1}{c}{ Blended Elemental Method (BEM) } & Pre-alloyed Powder Method (PA) \\
\hline Raw material powder & $\begin{array}{l}\text { Mixture of pure Ti powder and powders of alloying elements } \\
\text { or } \\
\text { Mixture of pure Ti powder and mother alloy powder }\end{array}$ & $\begin{array}{l}\text { Pre-alloyed powder } \\
\text { (No need for pure Ti powder) } \\
\text { (No need for powders of allloying elements) } \\
\text { (No need for mother alloy powder) }\end{array}$ \\
\hline Merit & Densified sintered material can be obtained & Price of pre-alloyed powder is relatively low \\
\hline Demerit & Price of low material powder is relatively high & Difficult to obtain densified sintered material \\
\hline Current status & $\begin{array}{l}\text { Technically established } \\
\text { However its application is limited }\end{array}$ & $\begin{array}{l}\text { Technically not established } \\
\text { No investigation has been reported }\end{array}$ \\
\hline
\end{tabular}

element by a powder metallurgical process and mechanical properties of the alloys are improved compared to copper free alloy ${ }^{5}$. Also, authors have reported the addition of iron to Ti-6Al-4V alloy influenced on the mechanical properties of the alloy drastically ${ }^{6}$. In this study, Ti-6Al-4V alloys containing 3.5 mass $\% \mathrm{Fe}$ iron and 4.0 mass $\% \mathrm{Cu}$ were produced through HIP and their properties were investigated.

\section{Experimental Procedure}

Ti-6Al-4V alloy powder was manufactured by HDH process using ingot turning chip of Ti-6Al-4V alloy as a starting material. Pulverization of hydrogenated titanium alloy was carried out using the closed circuit pulverizing device equipped with ACM Pulverizer ${ }^{\circledR}$ and MS micron separator of Hosokawa Micron Corporation under argon atmosphere. A schematic of equipment is indicated in Fig. 1. $400 \mathrm{~kg}$ hydrogenated titanium alloy was charged into the device and pulverization and sieving was carried out and $320 \mathrm{~kg}$ of classified powder between $10 \mu \mathrm{m}$ and $150 \mu \mathrm{m}$ was obtained. The yield of this process was $80 \%$. Then, pulverized Ti-6Al-4V hydrogenated powder was dehydrogenated by vacuum furnace and finally Ti-6Al-4V alloy powder was obtained.

Carbonyl iron powder made by BASF Corporation $(8.0 \mu \mathrm{m}$ of mean particle diameter) or cupper powder made by DOWA

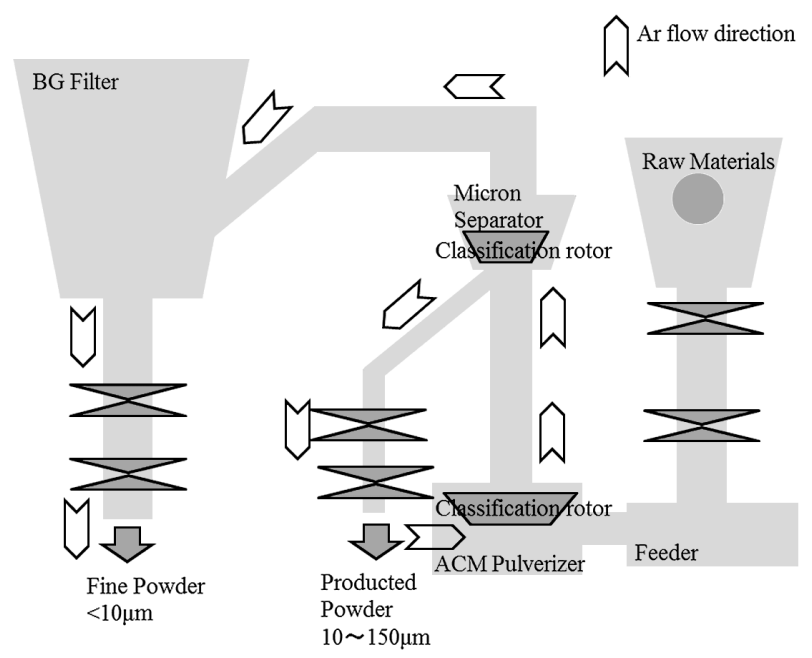

Fig. 1 Schematic illustration of pulverizing and classifying equipment (ACM closed circuit by Hosokawa Micron Corporation).
Electronics Materials CO., LTD (6.0 $\mu \mathrm{m}$ of mean particle diameter) was added to the Ti-6Al-4V alloy powder. Composition of iron and copper is 3.5 mass $\%, 4.0$ mass $\%$, respectively. The powder without iron or copper was also prepared for comparison purpose. These three kinds of powder were consolidated by HIP.

Each 3 powder lot was inserted into a metal capsule of a diameter of $150 \mathrm{~mm}$ and hot isostatically pressed to $130 \mathrm{~mm}$ of diameter at $1153 \mathrm{~K}$ under the pressure of $100 \mathrm{MPa}$ for $1 \mathrm{Hr}$. HIPped bars were hot forged to $100 \mathrm{~mm}$ of diameter and hot rolled to $22 \mathrm{~mm}$ of diameter and followed by heat treatment.

Heat treatment temperature was selected below the $\beta$ transformation point, $\mathrm{T}_{\beta},(1143 \mathrm{~K}$ in iron or copper containing alloys, $1223 \mathrm{~K}$ in iron or copper free alloy) and keeping time was $7.2 \mathrm{ks}$ and water cooled, or air cooled. A production flow is indicated in Fig. 2. A sample was taken from the way of the production process and the end product, and metallographic observation, microphotograph

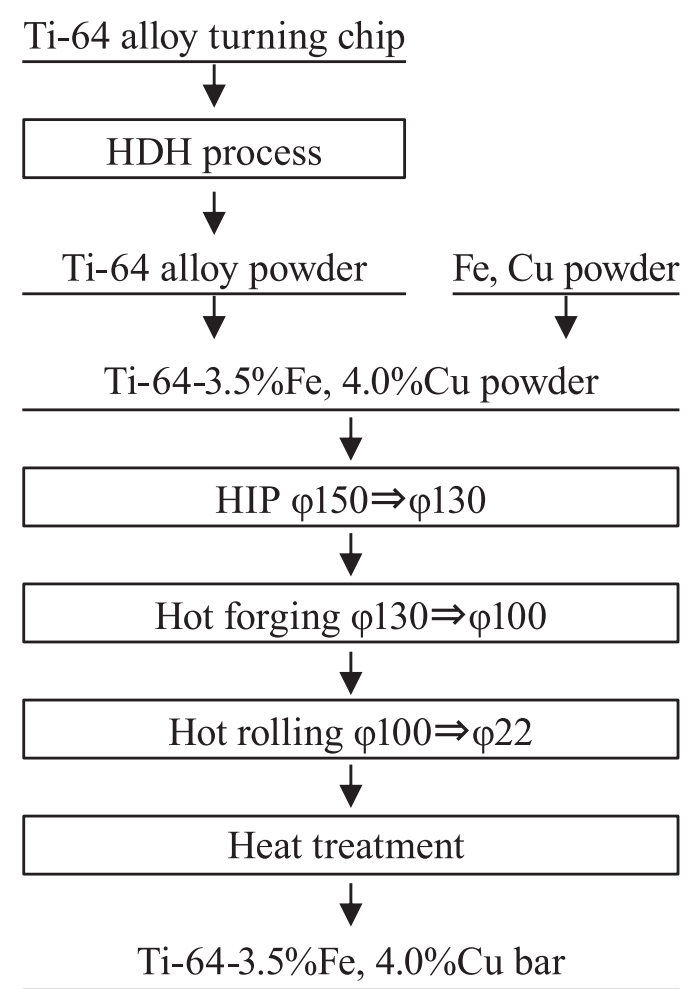

Fig. 2 Production flow chart of titanium alloy bars. 
observation, tensile test and fatigue test were performed. The existence ratio of $\beta$ phase was measured using the difference in the shades between $\alpha$ phase and $\beta$ phase in an optical microphotograph in the heat treated specimens. According to the report ${ }^{7,8)}, \alpha$ phase is observed white and $\beta$ phase black in the optical microscopic observation of the Ti-6Al-4V alloy.

\section{Experimental Results}

3.1 Chemical Composition and Density

Chemical analytical results of Ti-6Al-4V alloy powder and HIPped bars were shown in Table 2. Table 2 also shows AMS specification applied to Ti-6Al-4V alloy bar which is manufactured from ingot.
The content of iron and copper of each bar is within the target.

Both of powder and HIPped bars obtained by this study satisfies the AMS specification except oxygen. This is because the oxygen content in the starting ingot is $0.2 \%$, and oxygen content increases during the crushing process even the crushing is carried out under argon atmosphere.

Table 3 shows the size and density of HIPped specimens. Since the density of these HIPped specimens are very close to their theoretical one, it can be said that almost fully densification has achieved during the HIP treatment.

\subsection{Microstructure}

Microstructure of the material is indicated in Fig. 3 at each stage,

Table 2 Chemical analysis of titanium alloy powder and HIPped bars. AMS specification for Ti-6Al-4V alloy bar manufactured through ingot is also shown for the reference purpose. (unit $=$ mass $\%$ )

\begin{tabular}{|c|c|c|c|c|c|c|c|c|c|}
\hline \multicolumn{2}{|l|}{ Element } & $\mathrm{Al}$ & V & $\mathrm{Fe}$ & $\mathrm{Cu}$ & $\mathrm{O}$ & $\mathrm{C}$ & $\mathrm{N}$ & $\mathrm{Ti}$ \\
\hline \multicolumn{2}{|c|}{ Ti-64 Alloy Powder } & 6.2 & 4.2 & 0.2 & $<0.001$ & 0.3 & 0.005 & 0.012 & Bal. \\
\hline \multicolumn{2}{|l|}{ Ti-64-3.5Fe Bar } & 5.9 & 3.9 & 3.4 & $<0.001$ & 0.3 & 0.004 & 0.014 & Bal. \\
\hline \multicolumn{2}{|l|}{ Ti-64-4.0Cu Bar } & 6.0 & 4.1 & 0.2 & 4.0 & 0.3 & 0.006 & 0.015 & Bal. \\
\hline \multirow{2}{*}{ Reference AMS-4928 } & $\min$ & 5.5 & 3.5 & - & - & - & - & - & \multirow{2}{*}{ Bal. } \\
\hline & $\max$ & 6.75 & 4.5 & 0.3 & - & 0.2 & 0.08 & 0.05 & \\
\hline
\end{tabular}

Table 3 Size and relative density of the specimens after HIP treatment.

\begin{tabular}{ccccccc}
\hline Composition & Diameter/mm & Length/mm & Weight/kg & $\begin{array}{c}\text { Culculated } \\
\text { density/g/cm }\end{array}$ & $\begin{array}{c}\text { Theoretical } \\
\text { density/g/cm }\end{array}$ & $\begin{array}{c}\text { Relative } \\
\text { density/\% }\end{array}$ \\
\hline Ti64 & 128 & 805 & 46.3 & 4.47 & 4.43 & 100.9 \\
Ti64 + 3.5Fe & 128 & 806 & 47.4 & 4.57 & 4.50 & 101.6 \\
Ti64 + 4.0Cu & 129 & 810 & 48.5 & 4.58 & 4.52 & 101.3 \\
\hline
\end{tabular}

\begin{tabular}{|c|c|c|c|}
\hline & As HIP & After HT & As hot rolled \\
\hline Ti64+3.5Fe & 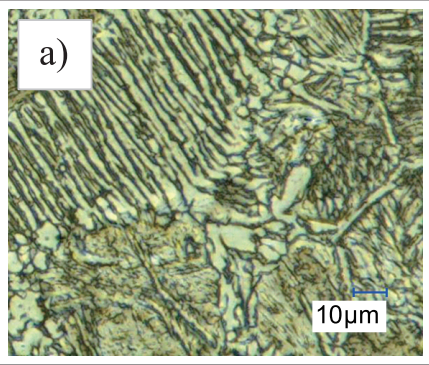 & 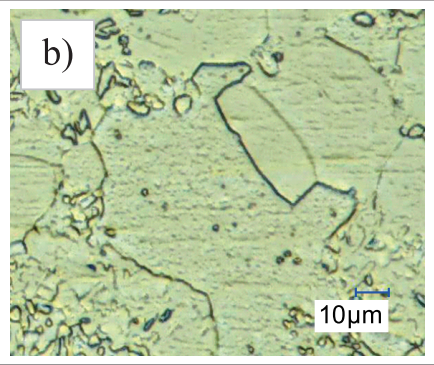 & 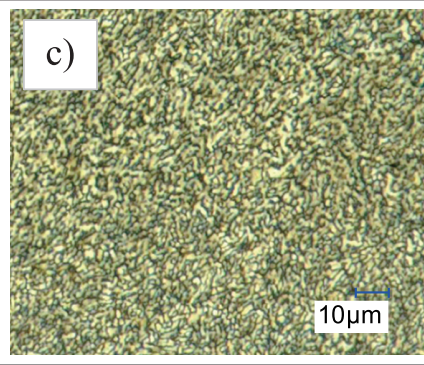 \\
\hline Ti64+4Cu & $(-4)=$ & & 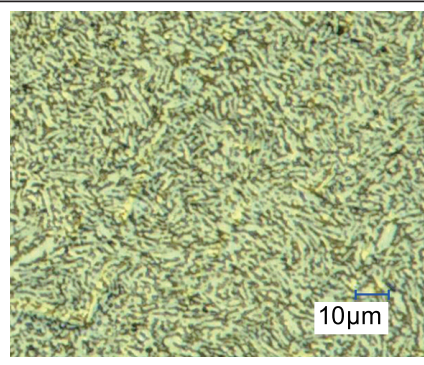 \\
\hline
\end{tabular}

Fig. 3 Microstructure of specimens.

The upper row: Ti-6Al-4V-3.5Fe alloy

The lower row: Ti-6Al-4V-4Cu alloy

(a) After HIP

(b) After the heat treatment at $1143 \mathrm{~K}$ without hot forging and hot rolling.

(c) After hot rolling 
(a) just after HIP, (b) heat treatment at $1143 \mathrm{~K}$ for $3.6 \mathrm{ks}$ after HIP and (c) after hot rolling. No pore was detected by observation of wide area of HIPped specimens. So it also can be said from the microstructure observation that almost fully densification has occurred during the HIP treatment. As described in the introduction, full densification is reported to be difficult by pre-alloyed powder metallurgy method ${ }^{9}$. However, these data show that HIP treatment as a sintering process resolves the difficulty in densification during sintering even in pre-alloyed powder metallurgy method because material receives higher stress than its deforming stress ${ }^{10)}$ during the HIP treatment.

Microstructure of iron and cupper containing alloys (Fig. 3) shows similar tendency. Just after the HIP treatment, microstructure consists of coarse prior $\beta$ phase, primary $\alpha$ phase along $\beta$ phase grain boundary and plate-like prior $\alpha$ phase inside $\beta$ phase. It is obvious that titanium alloy with such a microstructure lacks in elongation and is not suitable for the airplane application. Even when it is heat-treated, the microstructure isn't improved. Microstructure drastically changed through the hot rolling from $\phi 100 \mathrm{~mm}$ to $\phi 22 \mathrm{~mm}$, working ratio of $95 \%$. Prior $\beta$ phases disappear and turn into fine grains. However, recrystallization does not occur just after the hot rolling, it seems that heat treatment is necessary to obtain equi-axed grains.

Fig. 4 shows microstructure after the heat treatment of specimens containing iron or copper. Water cooled specimen shows the microstructure at the midway to full recrystallization and air-cooled specimen shows perfectly recrystallized equi-axis grains.
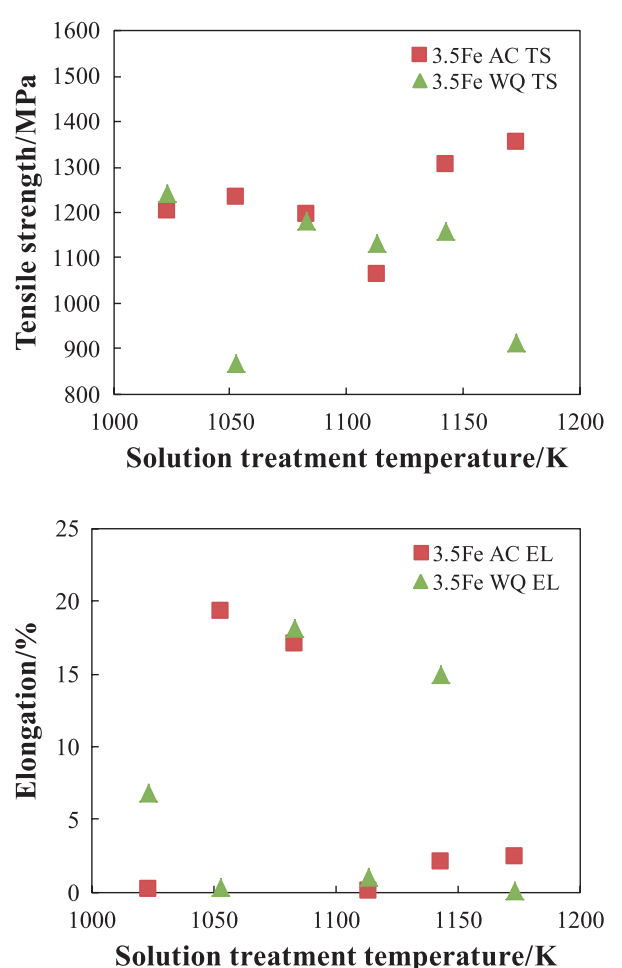

Fig. 5 Tensile properties of iron containing alloy under various cooling conditions and solution treatment temperatures.

\subsection{Tensile Property}

Test pieces for tensile test (by JIS-H4650) were cut down from the specimens after the heat treatment (air cooling and water cooling) and tensile test was carried out. Fig. 5 shows the results of iron containing alloy under several conditions. Tensile strength of air cooled specimen increases with increasing solution treatment temperature but in vice versa in water cooled specimen. $0.2 \%$ proof stress shows a similar behavior as tensile strength. Elongation and reduction area vary widely and it is difficult to detect the relationship between ductility and heat treatment condition from

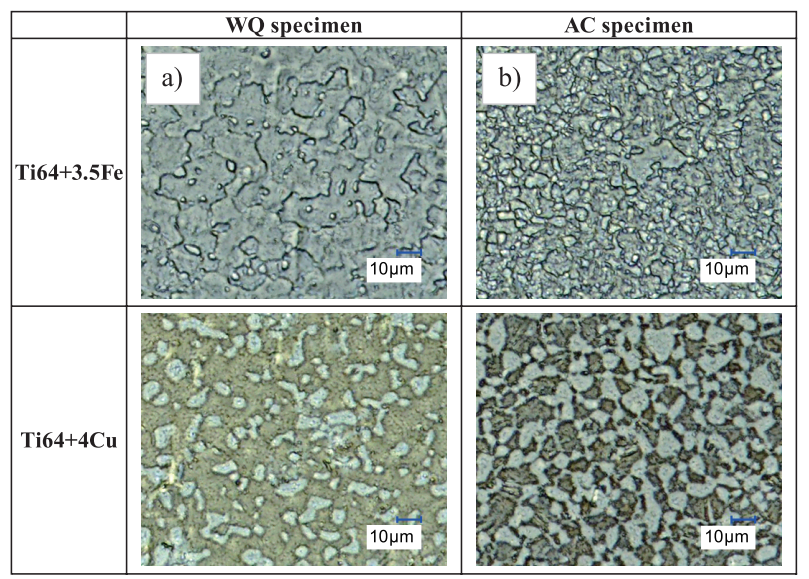

Fig. 4 Microstructure of specimens. The upper row: Ti-6Al-4V-3.5Fe alloy The lower row: Ti-6Al-4V-4Cu alloy (a)Water cooled specimen (b)Air cooled specimen
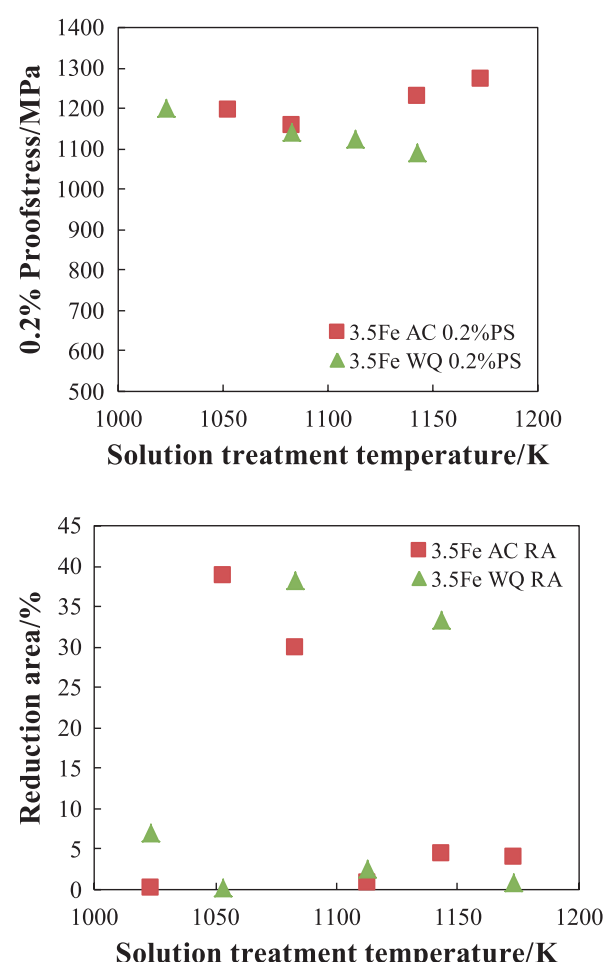

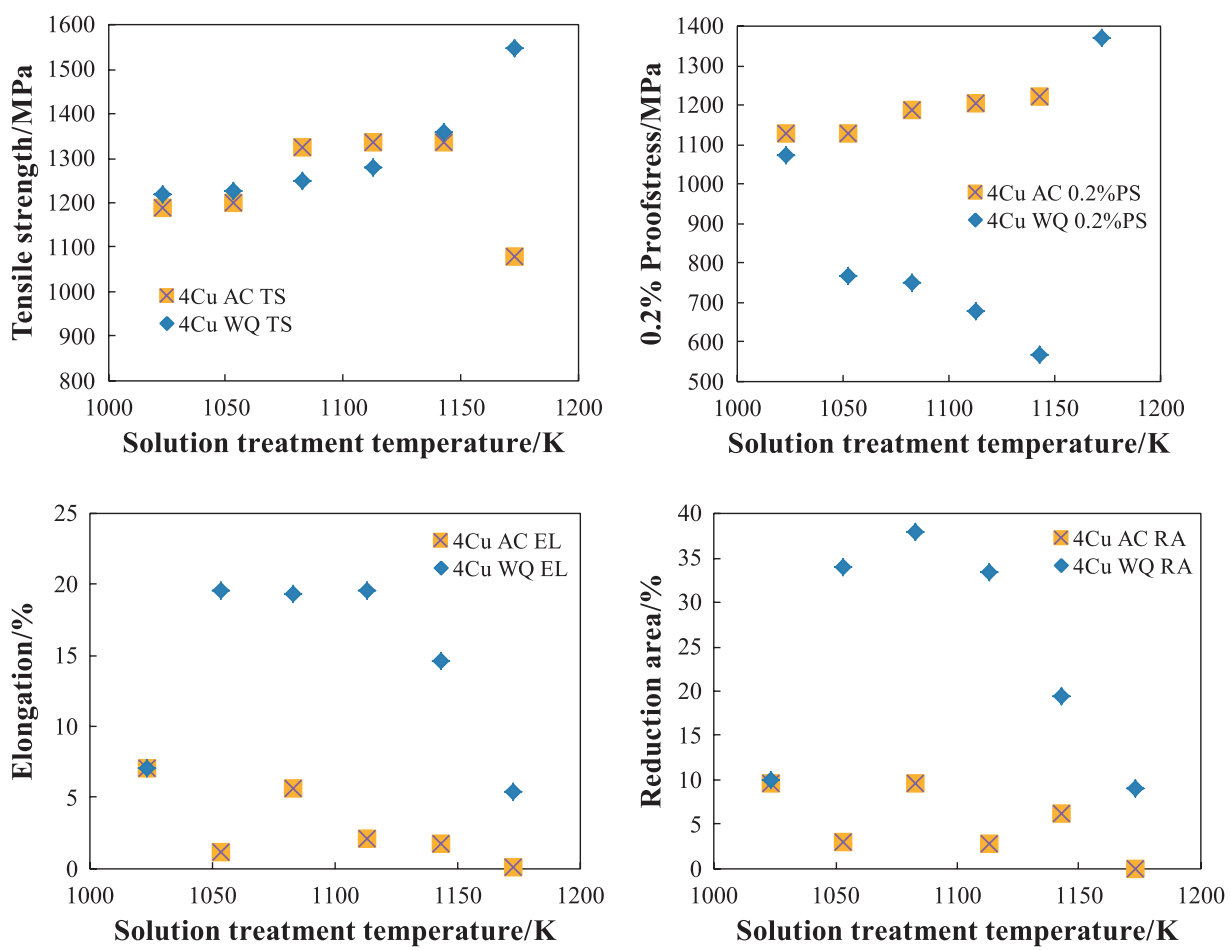

Fig. 6 Tensile properties of copper containing alloy under various cooling conditions and solution treatment temperatures.

only these results. But it can be said that the ductility of iron containing alloy is sensitive to heat treatment condition.

Fig. 6 shows tensile property of copper containing alloy under various heat treatment conditions. Tensile strength has no dependence on cooling condition, however, $0.2 \%$ proof stress shows different behavior between air cooling and water cooling. It increases with increasing solution treatment temperature in the air cooled specimen, and opposite tendency in water cooled specimen.

Elongation and reduction area also show different behavior between air cooling and water cooling like $0.2 \%$ proof stress. Maximum elongation values are $7 \%$ in air cooled specimen and $20 \%$ in water cooled specimen, respectively. Reduction area shows similar behavior to elongation. Maximum reduction area values are $10 \%$ in air cooled specimen and $38 \%$ in water cooled specimen, respectively.

\subsection{Fatigue Test}

Fig. 7 shows result of fatigue test of $3.5 \% \mathrm{Fe}$ containing alloy. High cycle fatigue test, cantilever type rotary bending fatigue test was carried out using specimens just after HIP process and air cooling at $1143 \mathrm{~K}$. Fatigue stresses of both specimens are approximately $600 \mathrm{MPa}$ at $1 \times 10^{7}$ cycles.

This value is equivalent as the reported values of wrought Ti-64 materials produced through ingot ${ }^{11)}$. This indicates that very sound titanium sintered material is produced by pre-alloyed powder method.

\section{Discussion}

Production of titanium alloy which contains high amount of iron or copper by pre-alloyed powder metallurgy method has completed

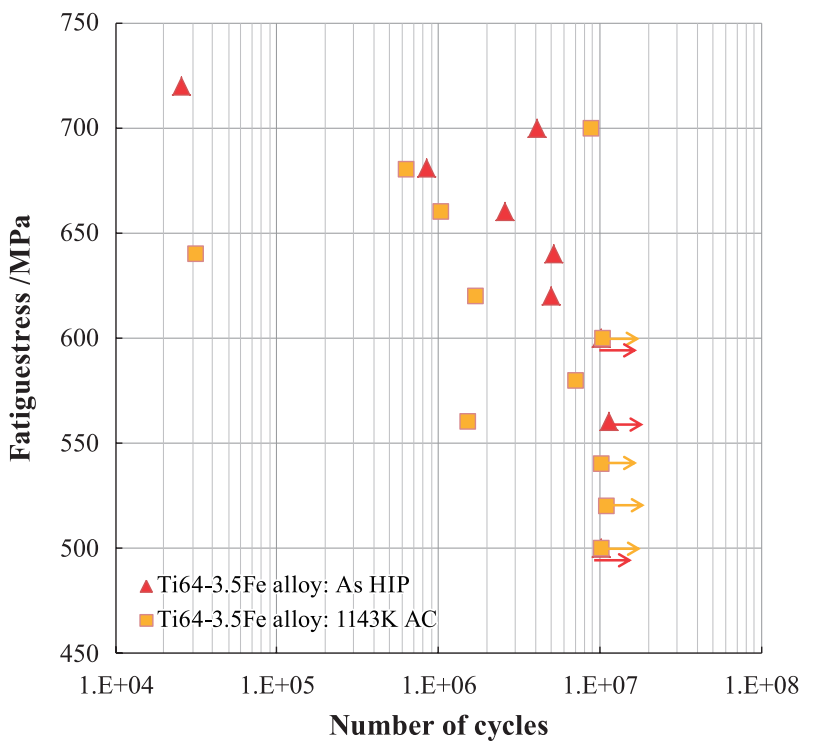

Fig. 7 Result of fatigue test.

not only by HIP treatment but also by hot extrusion ${ }^{6,12)}$. The comparison between HIP and hot extrusion seems to be beneficial in order to discuss tensile properties. Fig. 8 shows tensile test results of the specimens manufactured by HIP and by hot extrusion. Fig. 8 indicates that tensile property of $\mathrm{Fe}$ or $\mathrm{Cu}$ containing alloys after heat treatment possesses similar tendency regardless the production method. Therefor the tensile property of HIPped specimen was discussed referring to the hot extruded specimens. Fig. 9 shows $0.2 \%$ proof stress and elongation as a function of $\beta$ phase ratio of $\mathrm{Fe}$ containing alloy produced by hot extrusion ${ }^{6,12)}$. Difference 


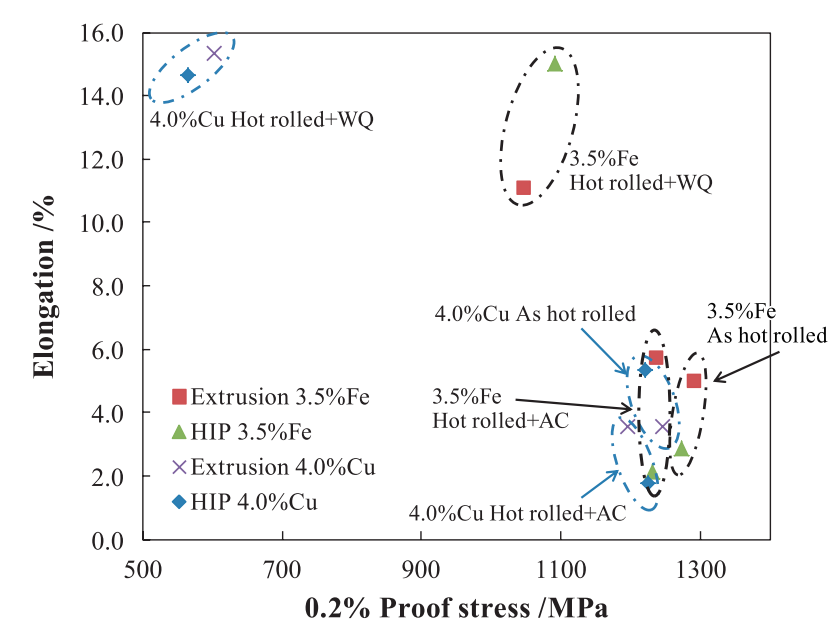

Fig. 8 Tensile properties of iron or copper containing alloys produced by HIP and hot extrusion.

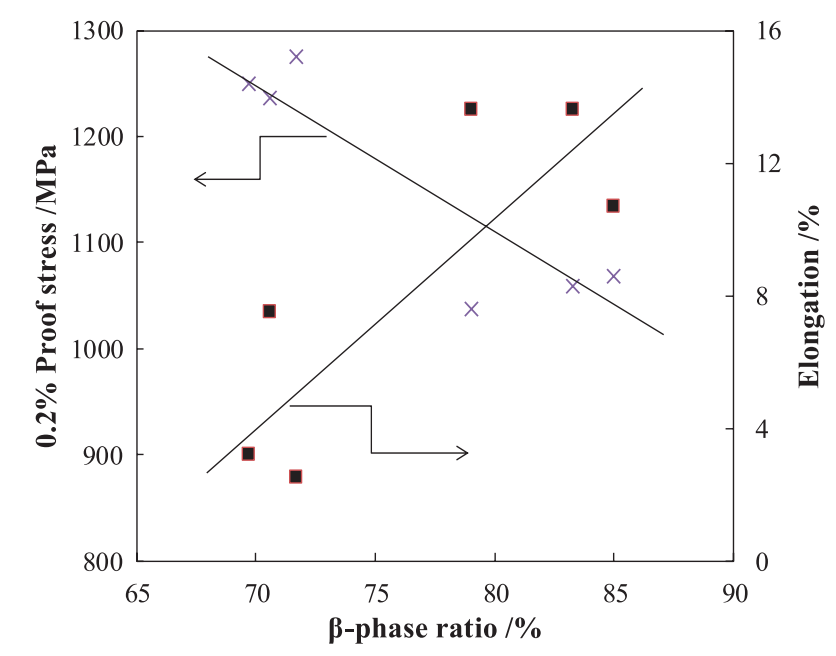

Fig. $9 \quad 0.2 \%$ proof stress and elongation as a function of $\beta$ phase ratio of iron containing alloy in the case of hot extrusion.

of $0.2 \%$ proof stress and ductility behavior between air cooled specimen and water cooled specimen was commonly observed both in HIPped specimen and hot extruded specimen. In the previous study ${ }^{6,12)}$, this phenomenon was explained to be caused by the difference of $\beta$ phase ratio.

Just after solution treatment at near the $\mathrm{T}_{\beta}$, the specimen becomes $\beta$ rich structure. In the case of air cooling, precipitation of $\alpha$ phase occurs during cooling and $\beta$ phase ratio decreases, meanwhile $\beta$ phase ratio is kept high in the case of water cooling. Further in this study, the addition of $\beta$ stabilizing elements increases $\beta$ phase ratio at higher temperature, optimization of heat treatment condition possibly control the strength and ductility of the specimen. Fig. 9 supports these circumstances. The addition of iron causes not only the reinforcement of alloy by the solid solution strengthening mechanism, but also the increase of $\beta$ phase ratio. This implies tensile properties of $\alpha+\beta$ dual phase alloy can be controllable by addition of $\beta$ stabilizing elements such as iron and copper.

\section{Conclusion}

In order to develop high-strength titanium alloy at low cost, Ti-6Al-4V-3.5Fe and Ti-6Al-4V-4.0Cu alloys have been produced by pre-alloyed powder metallurgy method.

(1) It is confirmed that HIP process is useful for consolidation method of pre-alloyed titanium alloy powder to almost its theoretical density.

(2) Addition of iron or copper reveals the possibility of highstrength titanium alloy with enough elongation. It has been proved that the effect of iron or copper is a control of $\beta$ phase ratio which drastically changes mechanical properties after heat-treatment.

(3) The fatigue stress is equivalent as the specimens reported in wrought materials.

These conclusions suggest that iron or copper containing titanium alloys produced by pre-alloyed powder metallurgy method possess very high potential in the application for aerospace or automobile.

\section{References}

1) W. Peter, Y. Yamamoto: "Net Shape Processing of Titanium Alloys for Enhanced Performance and Improved Affordability" ORNL/TM-2012(2013), 1-98.

2) R. Boyer, J. Williams: "Development in Research and Applications in the Titanium Industry in the USA", Proceedings of the $12^{\text {th }}$ World Conference on Titanium, L. Zhou, H. Chang, Y. Lu, D. Xu, Beijin, The Nonferrous Metals Society of China, (2011) 10-19.

3) C. Brice: "Net Shape Processing of Titanium Alloys for Enhanced Performance and Improved Affordability", Proceedings of the $12^{\text {th }}$ World Conference on Titanium, L. Zhou, H. Chang, Y. Lu, D. Xu, Beijin, The Nonferrous Metals Society of China, (2011) 1697-1703.

4) P. Whittaker: "Dynamet Technology approved by Boeing as qualified supplier for Powder Metallurgy titanium alloy products" IMPD net $2^{\text {nd }}$ May, 2012.

5) S. Sugawara, O. Kanou, H. Takatori, H. Ikeda, Y. Saimen, N. Yamana: "Development of Low-cost and High-strength Titanium Alloy by Powder Metallurgical Process" Proceedings of the $12^{\text {th }}$ World Conference on Titanium, L. Zhou, H. Chang, Y. Lu, D. Xu, Beijin, The Nonferrous Metals Society of China, (2011) 1759-1762.

6) M. Hayakawa, O. Kanou, N. Fukada: "Production of Highstrength Titanium Alloy by Pre-alloyed Powder Metallurgical Process" Proceedings of the $13^{\text {th }}$ World Conference on Titanium, San Diego, to be published.

7) T. Morita, K. Shinoda, K. Kawasaki, Y. Misaki: "Influence of Short-Time Duplex Heat Treatment on Fatigue Strength of Ti-6Al-4V Allot" Journal of Society of Materials Science, Japan, 56 (2007) 345-351.

8) L. M. Gammon, R. D. Briggs, J. M. Packard, K. W. Baston, R. 
Boyer, C. W. Domby: The Boeing Company. "Metallography and Microstructures of Titanium and Its Alloys" ASM Handbook, 9 (2004) 899-917.

9) Ma Quian: "Cold Compaction and Sintering of Titanium and its alloys for Near-Net Shape or Preform Fabrication” International Journal of Powder Metallurgy, 46 (2010) 29-44.

10) H. Suzuki, T. Ashina, K. Aoyagi, H. Fujii, K. Tanabe: "Hot Workability of Ti-6Al-4V Alloys" The Iron and Steel Institute of Japan, 86 (1986) 587-594.

11) M. J. Donachie: Titanium A Technical Guide, Second Edition, ASM International, 2000, 44.

12) O. Kanou, N. Fukada, M. Hayakawa: "Production of Highstrength Titanium Alloy Using Pre-alloyed Powders as a Starting Material”, J. Jpn. Soc. Powder Powder Metallurgy, 62 (2015) 365-370. 